\title{
Use of a level 3 portable monitor for the diagnosis and management of sleep-disordered breathing in an inpatient tertiary care setting
}

\author{
Marcus Povitz MD, R John Kimoff MD
}

M Povitz, RJ Kimoff. Use of a level 3 portable monitor for the diagnosis and management of sleep-disordered breathing in an inpatient tertiary care setting. Can Respir J 2014;21(2):96-100.

BACKGROUND: Sleep-disordered breathing (SDB) may impact the course of medical illness among hospitalized patients. Access to testing during hospitalization to assess this may be limited by wait times for laboratory polysomnography. Level 3 portable monitoring (PM) may provide an alternative.

OBJECTIVE: To assess the rate of technically adequate studies, diagnostic information obtained and impact on patient management of inpatient PM studies performed for SDB.

METHODS: A retrospective review of 114 PM (Embletta, Natus Inc, Canada) records from the past two years was performed. Studies were ordered by pulmonologists, initiated by respiratory therapists and performed unattended on inpatient units. Admitting diagnoses, indication for sleep study, diagnostic information obtained from recordings and change in clinical management subsequent to PM were determined from medical charts.

RESULTS: Of 114 studies reviewed, 99 (87\%) met predetermined criteria for adequate signal quality and duration. Five studies could not be interpreted due to inadequate data, yielding an overall success rate of 83\% (94 of 114). Of 86 studies performed for diagnosis, clinical and PM data supported a new diagnosis of SDB in 55 patients, of which $23(42 \%)$ were started on positive pressure therapy. Thirteen PM studies were performed during SDB treatment. All were technically adequate and six of 13 demonstrated new or persistent SDB. Results from PM testing informed clinical management during hospitalization in $70(61 \%)$ cases.

CONCLUSION: Unattended level 3 PM studies are technically feasible in hospitalized patients and may provide information that influences clinical management.

Key Words: Diagnosis; Inpatient; Portable monitors; Sleep apnea; Sleepdisordered breathing

Sleep-disordered breathing (SDB) encompasses a spectrum of disor$\checkmark$ ders including obstructive sleep apnea (OSA), central sleep apnea (CSA) and nocturnal hypoventilation; the most common is OSA (1). OSA has been shown to contribute to the severity of cardiovascular disease including stroke, coronary artery disease and heart failure (2-7), and in patients who refused therapy, excess cardiovascular mortality (2). In these reports, OSA severity increased the disease severity and, in the absence of treatment, was associated with excess morbidity and mortality $(8,9)$. This was largely normalized in patients who were compliant with therapy (10). Furthermore, OSA has been reported to contribute to prolonged hospital stays in orthopedic surgical patients (11). CSA is prevalent in heart failure and is associated with a poor prognosis. CSA may also be a therapeutic target; however, this remains controversial (12). Hypoventilation may present with acute respiratory decompensation in undiagnosed patients; these patients are at high risk for decompensation and intensive care unit admission, which may be preventable by rapid diagnosis and institution of therapy (13).

Clinical experience suggests that OSA, CSA and hypoventilation are prevalent among medical patients hospitalized for exacerbations of chronic diseases. Because SDB may be a factor that contributes to
L'utilisation d'un moniteur portable de niveau 3 pour diagnostiquer et prendre en charge les troubles respiratoires du sommeil chez des patients hospitalisés dans un centre de soins tertiaires

HISTORIQUE : Les troubles respiratoires du sommeil (TRS) peuvent contribuer à l'évolution d'une maladie chez les patients hospitalisés. L'accès aux examens pour évaluer le problème peut être limité pendant l'hospitalisation, en raison des temps d'attente pour être admissible à une polysomnographie en laboratoire. Les moniteurs portables (MP) de niveau 3 pourraient constituer une solution de rechange.

OBJECTIF : Évaluer le taux d'études pertinentes sur le plan technique, l'information diagnostique obtenue et les répercussions des études par MP effectuées pour traiter les TRS sur la prise en charge des patients hospitalisés. MÉTHODOLOGIE : Les chercheurs ont effectué une analyse rétrospective de 114 dossiers de MP (Embletta, Natus Inc, Canada) accumulés au cours des deux années précédentes. Les études avaient été demandées par des pneumologues, lancées par des inhalothérapeutes et effectuées sans surveillance dans les ailes d'hospitalisation. À partir des dossiers médicaux, les chercheurs ont déterminé les diagnostics à l'hospitalisation, les indications ayant justifié une étude du sommeil, l'information diagnostique obtenue par l'enregistrement et les modifications à la prise en charge clinique après l'utilisation du MP.

RÉSULTATS : Des 114 études analysées, 99 (87\%) respectaient les critères préétablis de qualité et de durée pertinentes du signal. Cinq études n'ont pas pu être interprétées en raison de données non pertinentes, ce qui s'est associé à un taux de réussite global de 83 \% (94 sur 114). Sur les 86 études diagnostiques effectuées, les données cliniques et obtenues grâce au MP ont étayé un nouveau diagnostic de TRS chez 55 patients, dont 23 (42\%) ont commencé à recevoir une thérapie en pression positive. Treize études par MP ont été effectuées pendant le traitement des TRS. Toutes étaient pertinentes sur le plan technique et six ont démontré de nouveaux TRS ou des TRS persistants. Les résultats des tests par MP ont contribué à la prise en charge clinique de 70 cas (61 \%) pendant l'hospitalisation.

CONCLUSION : Les études par MP de niveau 3 sans surveillance sont faisables sur le plan technique chez les patients hospitalisés et peuvent fournir de l'information qui influera sur la prise en charge clinique.

decompensation of comorbid conditions, it is occasionally necessary to evaluate patients while hospitalized for undiagnosed or undertreated SDB. In previous series, SDB was evaluated primarily by attended polysomnography (PSG) (14-18), although attended level 3 monitoring has been reported (19-22). These studies showed that, in referred patients, there was a high incidence of SDB.

A limiting factor in the diagnosis of SDB is the resource-intensive requirement of PSG and other forms of attended monitoring and, for hospitalized patients, other medical needs that may not permit them to be moved to a sleep laboratory. Portable monitors are validated for the diagnosis of moderate to severe OSA, and have high levels of agreement with attended PSG in outpatients with limited comorbidity $(23,24)$. Moreover, the American Academy of Sleep Medicine endorses their use in hospitalized patients when in-laboratory PSG is not possible, although the evidence supporting this is limited (24). Thus, while the use of portable monitoring (PM) in hospitalized patients may facilitate patient care, there remains a scarcity of studies evaluating feasibility, reliability and outcomes.

At our institution, we previously evaluated SDB in inpatients using recording oximetry or delayed evaluation until complete PSG was 
available. Problems with this approach included the relative inaccuracy of oximetry for SDB diagnosis and long wait times for evaluation in the sleep laboratory. Therefore, we instituted inpatient recordings using a level 3 portable device (Embletta, Natus Inc, Canada). The present study was a retrospective chart review conducted to evaluate this approach. Our objective was to assess whether in-hospital, unattended level 3 PM could provide timely, accurate data to guide management of SDB. The specific aims were to determine the technical success rate of unattended level 3 PM applied in-hospital, and to evaluate the diagnostic information obtained from these recordings and the impact on inpatient management.

\section{Design and study population}

\section{METHODS}

The present study was approved by the research ethics board. A retrospective analysis of inpatient PM studies was performed between January 2010 and December 2011 at three tertiary hospitals, including all subjects from two sites and a subset of studies from the third (where the largest number of studies was performed) to provide a balanced distribution of study indications and results reflective of the three sites. The subset of studies at the third site was randomly selected from a list of all inpatient PM studies without consideration of study indication, success rate or result. All PM sleep studies available from the third site were subsequently screened for technical quality using a priori criteria (see below) to ensure that the random sample was, in fact, representative of the studies performed at that site.

\section{Inclusion criteria}

Hospital inpatients $>18$ years of age who had been assessed by a pulmonologist, and underwent an inpatient overnight evaluation using PM for SDB, and whose hospital record was available for analysis were included in the present study.

\section{Level 3 PM studies}

PM studies were conducted using the Embletta X10 (Natus Inc, Canada) device, which includes recording of pulse oximetry with derived heart rate, snoring and nasal airflow using a nasal pressure catheter, rib cage and abdominal motion using autocalibrating respiratory inductance plethysmography, body position and actigraphy. This monitor has previously been validated for use in the diagnosis and management of $\operatorname{SDB}(25,26)$. For studies investigating positive pressure therapy, the pressure catheter was interposed via $\mathrm{T}$ connector in the patient's circuit for continuous pressure measurement. The recorder was installed at the bedside by a respiratory therapist or sleep laboratory technologist. The patient was instructed in the use of the device, and there was limited involvement of nursing and/or respiratory staff through the night to ensure that the position of the sensors were maintained. In one institution (smaller, with a more favourable respiratory therapist staffing ratio), the device was verified by the respiratory therapist following installation at least once during the night, while at the other two sites, respiratory therapist verification was rarely performed after initial installation.

PM recordings were scored manually by a trained PSG technologist, with review by an expert physician. For purposes of the present study, all PM studies were reviewed by the investigators. Respiratory events were scored according to modified Chicago criteria (27). The channel of preference for respiratory event scoring on diagnostic studies was nasal pressure. For studies on positive pressure, and for diagnostic studies with supplemental oxygen with suboptimal nasal pressure signal quality, the respiratory inductance sum channel was used. Hypopneas were scored as either a $50 \%$ reduction from baseline flow without a requirement for desaturation, or a $30 \%$ to $50 \%$ reduction in flow with associated $>3 \%$ oxygen desaturation. Autonomic hypopneas were also scored, which were defined as a reduction in airflow $>30 \%$ associated with an increase in heart rate of $\geq 6$ beats/min (28). Severity of apnea was graded based on the apnea hypopnea index (AHI); an AHI threshold $\geq 15$ was used for diagnosis of SDB. A diagnosis of OSA was made when $>50 \%$ of the events were obstructive. A diagnosis of CSA was made when $>50 \%$ of the events were central. For the present analysis, a diagnosis of 'nocturnal hypoventilation' was based on a clear decline in oygen saturation $\left(\mathrm{SaO}_{2}\right)$ from awake baseline values to an $\mathrm{SaO}_{2}<90 \%$ for $\geq 30 \%$ of the night, in the absence of supplemental oxygen therapy (29). When baseline $\mathrm{SaO}_{2}$ was low throughout the recordings, in circumstances in which the patient was receiving supplemental oxygen or when desaturations were very abrupt with rapid recovery (eg, as with removal of supplemental oxygen), this was termed 'indeterminate hypoxemia'.

\section{Criteria for technical adequacy}

Criteria for technically inadequate studies were established before the present analysis for use in the ambulatory monitoring program. These criteria included studies with a complete absence of recorded data or in which the data collected were unreliable or insufficient for diagnosis. Specific criteria for the latter were study analysis time $<4 \mathrm{~h}, \mathrm{SaO}_{2}$ signal present $<30 \%$ of the recording time or $<3 \mathrm{~h}$, or airflow and/or effort band channels present $<50 \%$ of recording time or $<3 \mathrm{~h}$.

\section{Clinical chart review}

Medical charts and the electronic health record were reviewed for demographic data, clinical information including admitting diagnosis, evolution of this condition, other comorbidities and treatment relevant to level 3 sleep recording results including oxygen and positive pressure treatment. PM study results were considered to have been applied if there was a note describing the outcome in the chart, or there was an intervention documented that was consequent to the outcome of the PM study.

\section{Statistical analysis}

Standard descriptive statistics were performed to characterize the patient population, PM recording data, clinical data and study outcomes. Between-group comparisons were performed using the $t$ test for normally distributed variables and the Mann-Whitney rank sum test for non-normally distributed data. Proportions were compared using the $\chi^{2}$ test; $\mathrm{P}<0.05$ was considered to be statistically significant.

\section{RESULTS}

A total of 116 PM recordings were reviewed. However, two subjects were excluded from further analysis because the medical charts could not be obtained, yielding 114 subjects. Subject characteristics, admitting diagnoses and comorbidities are summarized in Table 1. Respiratory and cardiac conditions were the most common admitting diagnoses and the most prevalent comorbidities. PM studies were typically performed following initial stabilization and treatment for the admitting condition, mostly on medical or surgical wards with a minority (approximately 7\%) performed in the intensive care unit.

Of the 114 PM recordings analyzed, 101 were performed for diagnosis, while 13 were performed to evaluate adequacy of treatment for SDB. The most common indications for diagnostic studies were suspected OSA (73\%) and nocturnal hypoventilation (14\%). For 6\%, no clear indication for the PM study was documented in the chart. For diagnostic studies, $37 \%$ of subjects were receiving supplemental oxygen. For the 13 studies investigating therapy, the treatments evaluated were continuous positive airway presure (CPAP) $(n=8)$, bilevel positive airway presure $(n=4)$ and servoventilation $(n=1)$. Five of these patients were receiving supplemental oxygen.

\section{Technical success rates}

Of the 114 PM studies, 15 (13\%) were technically inadequate using a priori criteria (Figure 1), yielding a technical success rate of $87 \%$. For the 15 inadequate studies, no data were recorded $(n=3)$ due to battery problems or programming errors, the recording length was inadequate (early removal of equipment $[n=3]$ ), or there was failure of one or more of the recording channels $(n=9)$, most commonly pulse oximetry. In two of these subjects, PM studies were subsequently repeated successfully. On review by the investigators, an additional five PM studies 
TABLE 1

Baseline characteristics $(n=114)$

\begin{tabular}{|c|c|c|c|}
\hline \multicolumn{2}{|l|}{ Male sex, n (\%) } & \multicolumn{2}{|l|}{$60(53)$} \\
\hline \multicolumn{2}{|l|}{ Age, years, mean \pm SD } & \multicolumn{2}{|l|}{$65 \pm 14.7$} \\
\hline \multicolumn{2}{|c|}{ Time admitted before portable monitoring, days, median (interquartile range) } & \multicolumn{2}{|l|}{$7(3-14)$} \\
\hline Chronic obstructive pulmonay disease exacerbation & $20(18)$ & Hypertension & $76(67)$ \\
\hline Congestive heart failure & $19(16)$ & Diabetes mellitus & $49(43)$ \\
\hline Pneumonia & $8(7)$ & Chronic obstructive pulmonay disease & $42(37)$ \\
\hline Hypoventilation syndrome & $5(4)$ & Atrial fibrillation & $22(19)$ \\
\hline Asthma exacerbation & $4(4)$ & Sleep-disordered breathing & $20(18)$ \\
\hline Neurosurgery & $4(4)$ & Dyslipidemia & $14(12)$ \\
\hline Cardiac surgery & $3(3)$ & Congestive heart failure & $20(18)$ \\
\hline Stroke & $5(4)$ & Cerebrovascular disease & $14(12)$ \\
\hline Syncope & $2(2)$ & Asthma & $13(11)$ \\
\hline
\end{tabular}

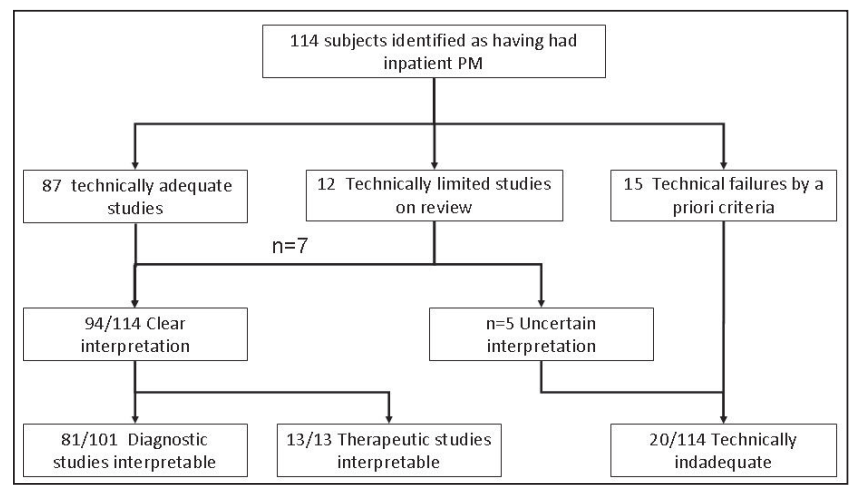

Figure 1) Technical success rate of inpatient portable monitoring (PM)

were deemed uninterpretable for technical reasons (absence of data from effort bands, precluding distinction between obstructive and central events), yielding an overall technical success rate of $82 \%$. Of note, all studies performed on SDB treatment were technically adequate (Figure 1). The rate of technically inadequate studies varied slightly but not significantly across the three study sites $(8 \%, 11 \%$ and $\left.21 \% ; \chi^{2} \mathrm{P}=0.16\right)$. The lowest rate was observed at the smallest institution, where systematic verification of the device was performed at least once during the night, while the highest rate was at a large institution performing a similar volume of studies annually but where systematic verification at least once during the night was not feasible due to staffing ratios.

There were no statistically significant differences between subjects with technically successful versus unsuccessful PM with respect to sex, age, length of stay, time from admission at which PM was performed, admitting diagnoses or comorbidities. The median time from admission to performance of PM was similar (seven days; interquartile range [IQR] three to 13 days for successful studies and IQR four to 17 days $[\mathrm{P}=0.61]$ for unsuccessful studies). There was a trend to a longer length of stay for unsuccessful studies, with median length of stay of 13 days (IQR seven to 34 days) for subjects with successful studies and 17 days (IQR nine to 43 days) $(\mathrm{P}=0.26)$ for unsuccessful studies.

\section{Diagnostic information obtained from PM studies}

The diagnostic information obtained from PM studies is shown in Table 2. The most common diagnosis was OSA. There was baseline/ inter-event oxygen desaturation in 23 of the 48 cases. CSA was identified in five subjects. Several studies without significant apnea-hypopnea
TABLE 2

Interpretation of portable monitoring studies

\begin{tabular}{lcl}
\hline & $\begin{array}{c}\text { Diagnostic } \\
(\mathbf{n}=\mathbf{1 0 1})\end{array}$ & $\begin{array}{c}\text { Therapeutic } \\
(\mathbf{n}=13)\end{array}$ \\
\hline Obstructive sleep apnea & $48(48)$ & $1(8)$ \\
Central sleep apnea & $5(5)$ & $2(15)$ \\
Nocturnal hypoventilation & $2(2)$ & $3(23)$ \\
Indeterminate hypoxemia & $4(4)$ & $0(0)$ \\
No diagnostic abnormality & $22(22)$ & $7(54)$ \\
Technical limitation or technical failure & $20(20)$ & $0(0)$ \\
\hline
\end{tabular}

Data presented as $n(\%)$

met criteria for isolated hypoventilation or showed indeterminate hypoxemia. A new SDB diagnosis (OSA, CSA and/or nocturnal hypoventilation) was identified in 55 of the 101 diagnostic studies performed. A wide range of SDB severity was identified (Table 3). Among patients with a new diagnosis of SDB, the mean AHI was $41.9 \pm 26.8$ events/h.

PM studies on therapy (Tables 2 and 3) confirmed the adequacy of current treatment in approximately one-half of subjects, while the remaining studies provided evidence for new or persistent SDB.

Clinical application of PM study results

The application of study results is depicted in Figure 2. For diagnostic $\mathrm{PM}$, the study results were incorporated into patient management during the same admission for 59 (73\%) of the 81 technically adequate PM studies. Results from $16 \%$ were applied either in subsequent admissions or outpatient visits, while in the remaining $14 \%$, it was not possible to determine from chart review whether the PM result influenced management either in-hospital or subsequently.

For the 20 diagnostic PM studies considered to be technically inadequate at the authors' review (Figure 1), data from six (30\%) were evaluated by the treating physician as providing pertinent information, and were applied to patient care (Figure 2).

In 23 (42\%) of the 55 new SDB cases identified by PM, CPAP was initiated while still in-hospital and, in one case, oxygen was prescribed for CSA. In 13 of 22 (59\%), there was documented continued CPAP use postdischarge. Of the remaining 33 (60\%) cases of new SDB diagnosis, treatment was deferred until discharge or outpatient follow-up. Fifteen of 33 (45\%) had an attempt at treatment, with six of $15(40 \%)$ starting CPAP successfully.

For the six PM studies performed on treatment for SDB that revealed new or persistent SDB (Table 2), SDB treatment was modified in five $(83 \%)$ subsequent to the PM recording. 
TABLE 3

Summary results of technically adequate portable monitoring

\begin{tabular}{lcc}
\hline & \multicolumn{2}{c}{ Study } \\
\cline { 2 - 3 } & Diagnostic $(\mathbf{n}=\mathbf{8 1})$ & Therapeutic $(\mathbf{n}=\mathbf{1 3})$ \\
\hline Recording time, h & $7.4 \pm 1.3$ & $7.1 \pm 0.8$ \\
Index time* $\mathrm{h}$ & $7.0 \pm 1.3$ & $6.8 \pm 0.9$ \\
Recording supine, \% & $56 \pm 38$ & $62 \pm 38$ \\
Apnea-hypopnea index & $27.6 \pm 27.0$ & $9.7 \pm 9.3$ \\
Apnea index & $7.9 \pm 15.1$ & $3.8 \pm 8.1$ \\
Hypopnea index & $20.1 \pm 21.3$ & $5.8 \pm 6.2$ \\
$4 \%$ oxygen desaturation index & $17.4 \pm 20.6$ & $4.5 \pm 6.7$ \\
Mean $\mathrm{SaO}_{2}, \%$ & $91 \pm 4$ & $93 \pm 3$ \\
Nadir $\mathrm{SaO}_{2}, \%$ & $76 \pm 9$ & $82 \pm 4$ \\
Percent of recording $\mathrm{SaO}_{2}<90 \%$ & $31.7 \pm 33.8$ & $22.3 \pm 30.4$
\end{tabular}

Data presented as mean $\pm S D$. *Index time $=$ total recording time - time with high actigraphy signal \pm movement/wakefulness. $\mathrm{SaO}_{2}$ Oxygen saturation

\section{Subsequent outpatient PSG}

Of the 114 PM subjects, 11 who underwent subsequent outpatient PSG in the hospital system were identified. In eight of 11 (73\%), the findings were concordant with the in-hospital PM study. Of the eight subjects with concordant studies, four were diagnostic (concordant for diagnosis and severity category of OSA $[n=3]$ and CSA $[n=1])$ and four were studies on therapy (concordant for condition and CPAP level). For the three subjects with discordant studies, the recordings were diagnostic: in two, there was no diagnostic abnormality on PM, but moderate-severe OSA on PSG; in the third, PM showed severe Cheyne-Stokes respiration-CSA while subsequent PSG after six months of optimal cardiac medication showed mild OSA.

\section{DISCUSSION}

The results of the present retrospective analysis show that unattended level 3 PM studies performed in hospitalized patients with medical comorbidities are technically feasible. Furthermore, a substantial proportion of these studies yielded diagnostic information that was applied by treating physicians to initiate or modify SDB treatment.

Overall, our rate of technically inadequate studies was $18 \%$ (20 of 114). Outpatient studies performed through our institution using the same PM device had a failure rate of $1 \%$ to $7 \%$ in monthly samples taken from the same period. However, our inpatient rate compares favourably with previous outpatient validation studies using the same device, showing failure rates of $18 \%$ and $17 \%(25,26)$.

The current literature on inpatient evaluation of SDB is limited. Several studies reported using full PSG (14-18) to evaluate patients with diverse admitting diagnoses, although few details on comorbid illness are provided. There was a high prevalence of SDB among the inpatients studied (14-18). Little data are provided on subsequent treatment, although Goring and Collop (14) initiated treatment in $10 \%$ of patients studied (contrasting with $42 \%$ of new SDB patients in the present study). Two groups have previously reported use of attended inpatient level 3 PM (19-22). Khayat et al $(19,20)$ evaluated SDB in decompensated heart failure. Subjects with OSA identified by PM were randomly assigned to automatic positive airway pressure versus standard treatment, with significant benefit to left ventricular ejection fraction (20). Parra et al $(21,22)$ used attended PM to evaluate SDB poststroke. Subjects with OSA were randomly assigned to CPAP versus conventional treatment, with benefit from CPAP to functional neurological recovery and delay of subsequent cardiovascular events (21). Thus, while limited, these studies suggest that inpatient PM is useful for the management of SDB, consistent with our findings.

The retrospective design of the present clinically based study was associated with several limitations, including diverse comorbidities and study indications, and variable postdischarge follow-up. Another limitation was the lack of systematic simultaneous or postdischarge PSG to validate the inpatient PM results. However, it is noteworthy that our centre performs 30 outpatient studies per week using the

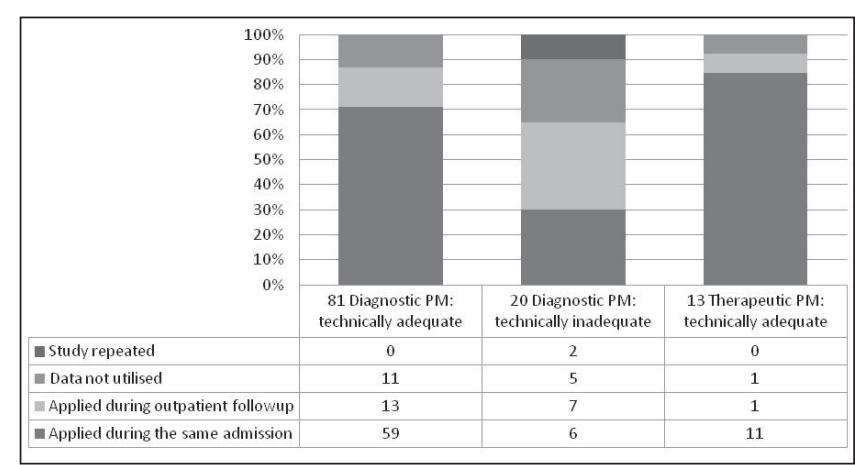

Figure 2) Clinical application of portable monitoring (PM) results

Embletta device (70\% diagnostic, remainder on positive airway pressure therapy [approximately 1500 studies per year]). Therefore, we have considerable experience with interpretation of Embletta recordings in a diversity of subjects, and a large body of clinical PSG data performed subsequent to PM recordings to inform PM interpretation. We are, therefore, confident of our interpretations of the inpatient PM recordings. A small proportion $(n=11)$ of our subjects did undergo subsequent PSG, and the majority (73\%) were concordant with the inpatient PM study. For the three subjects with discordant results, two with suspected OSA and negative PM subsequently underwent PSG consistent with recommended practice $(23,24)$ and were positive, and the third subject showed resolution of Cheyne-Stokes respirationCSA with heart failure treatment at follow-up PSG, as has previously been reported (12). While limited, these findings point to the fact that acute medical illness and hospitalization may influence the results of PM studies compared with more stable outpatient evaluations. Potential factors accounting for this include poor sleep quality or reduced sleep duration in hospital, which could reduce the sensitivity of PM, or cardiorespiratory decompensation which may alter gas exchange, fluid status and, therefore, findings on PM. Thus, consideration should be given in individual cases to performing follow-up outpatient studies to evaluate SDB evolution after inpatient PM recording. However, our finding that approximately three-quarters of the followup PSG results were concordant suggests that inpatient PM studies can inform care when interpreted in conjunction with clinical findings.

\section{SUMMARY}

The findings of the present study support the concept that level 3 PM can be used to guide timely assessment and management of SDB in hospitalized patients. However, our results also indicate that further studies are required to better define the role of PM in inpatient management of SDB. Issues warranting further study include: optimal recording configurations for specific forms of SDB and the identification of sensors less prone to data loss in unattended settings; the influence of comorbid conditions, acute medical illness and sleep disruption on the reliability of PM in relation to full PSG; and the optimal timing of PM recording in relation to the evolution of comorbid illness. PM-based protocols could ultimately be used to address key questions such as whether early diagnosis and treatment of SDB in the inpatient setting reduces length of stay and improves rehospitalization and other long-term clinical outcomes.

ACKNOWLEDGEMENTS: The authors acknowledge the contribution of Allen Olha to PM analysis and data management, the contribution of Naftaly Naor and other members of the Sleep Laboratory technical staff to PM installation and scoring, and the contribution to PM recordings of the Respiratory Therapy departments of the Montreal General and Montreal Chest Institute sites.

FUNDING: No financial support was received to fund this research. 


\section{REFERENCES}

1. Jennum P, Riha RL. Epidemiology of sleep apnoea/hypopnoea syndrome and sleep-disordered breathing. Eur Respir J 2009;33:907-14.

2. Marin JM, Carrizo SJ, Vicente E, et al. Long-term cardiovascular outcomes in men with obstructive sleep apnoea-hypopnoea with or without treatment with continuous positive airway pressure: An observational study. Lancet 2005;365:1046-53.

3. Marin JM, Soriano JB, Carrizo SJ, et al. Outcomes in patients with chronic obstructive pulmonary disease and obstructive sleep apnea: The overlap syndrome. Am J Respir Crit Care Med 2010;182:325-31.

4. Babu AR, Herdegen J, Fogelfeld L, et al. Type 2 diabetes, glycemic control, and continuous positive airway pressure in obstructive sleep apnea. Arch Int Med 2005;165:447-52.

5. Wang H, Parker JD, Newton GE, et al. Influence of obstructive sleep apnea on mortality in patients with heart failure. J Am Coll Cardiol 2007;49:1625-31.

6. Martinez-Garcia MA, Soler-Cataluna JJ, Ejarque-Martinez L, et al. Continuous positive airway pressure treatment reduces mortality in patients with ischemic stroke and obstructive sleep apnea: A 5-year follow-up study. Am J Respir Crit Care Med 2009;180:36-41.

7. Pillai A, Warren G, Gunathilake W, Idris I. Effects of sleep apnea severity on glycemic control in patients with type 2 diabetes prior to continuous positive airway pressure treatment. Diabetes Technol Ther 2011;13:945-9.

8. McNicholas WT, Bonsigore MR. Sleep apnoea as an independent risk factor for cardiovascular disease: Current evidence, basic mechanisms and research priorities. Eur Respir J 2007;29:156-78.

9. Somers VK, White DP, Amin R, et al. Sleep apnea and cardiovascular disease: An American Heart Association/American College Of Cardiology Foundation Scientific Statement from the American Heart Association Council for High Blood Pressure Research Professional Education Committee, Council on Clinical Cardiology, Stroke Council, and Council On Cardiovascular Nursing. Circulation 2008;118:1080-111.

10. Gay PC. Sleep and sleep-disordered breathing in the hospitalized patient. Respir Care 2010;55:1240-54.

11. Gupta RM, Parvizi J, Hanssen AD, Gay PC. Postoperative complications in patients with obstructive sleep apnea syndrome undergoing hip or knee replacement: A case-control study. Mayo Clin Proc 2001;76:897-905.

12. Kee K, Naughton MT. Heart failure and sleep-disordered breathing: Mechanisms, consequences and treatment. Curr Opin Pulm Med 2009; 15:565-70.

13. Piper AJ, Grunstein RR. Obesity hypoventilation syndrome: Mechanisms and management. Am J Respir Crit Care Med 2011;183:292-8.

14. Goring K, Collop N. Sleep disordered breathing in hospitalized patients. J Clin Sleep Med 2008;4:105-10.
15. Padeletti M, Green P, Mooney AM, et al. Sleep disordered breathing in patients with acutely decompensated heart failure. Sleep Med 2009;10:353-60.

16. Richards KC, Anderson WM, Chesson AL Jr, Nagel CL. Sleep-related breathing disorders in patients who are critically ill. J Cardiovasc Nurs 2002;17:42-55.

17. Farney RJ, Walker JM, Cloward TV, et al. Polysomnography in hospitalized patients using a wireless wide area network. J Clin Sleep Med 2006;2:28-34.

18. Brooks D, Davis L, Vujovic-Zotovic N, et al. Sleep-disordered breathing in patients enrolled in an inpatient stroke rehabilitation program. Arch Phys Med Rehabil 2010;91:659-62.

19. Khayat RN, Jarjoura D, Patt B, et al. In-hospital testing for sleepdisordered breathing in hospitalized patients with decompensated heart failure: Report of prevalence and patient characteristics. J Card Fail 2009;15:739-46.

20. Khayat RN, Abraham WT, Patt B, et al. In-hospital treatment of obstructive sleep apnea during decompensation of heart failure. Chest 2009;136:991-7.

21. Parra O, Sanchez-Armengol A, Bonnin M, et al. Early treatment of obstructive apnoea and stroke outcome: A randomised controlled trial. Eur Resp J 2011;37:1128-36.

22. Parra O, Arboix A, Bechich S, et al. Time course of sleep-related breathing disorders in first-ever stroke or transient ischemic attack. Am J Respir Crit Care Med 2000;161:375-80.

23. Collop NA. Portable monitoring for the diagnosis of obstructive sleep apnea. Curr Opin Pulmon Med 2008;14:525-9.

24. Collop NA, Anderson WM, Boehlecke B, et al. Portable Monitoring Task Force of the American Academy of Sleep Medicine. Clinical guidelines for the use of unattended portable monitors in the diagnosis of obstructive sleep apnea in adult patients. J Clin Sleep Med 2007;3:737-47.

25. Dingli K, Coleman EL, Vennelle M, et al. Evaluation of a portable device for diagnosing the sleep apnoea/hypopnoea syndrome. Eur Respir J 2003;21:253-9.

26. Skomro RP, Gjevre J, Reid J, et al. Outcomes of home-based diagnosis and treatment of obstructive sleep apnea. Chest 2010;138:257-63.

27. Sleep-related breathing disorders in adults: Recommendations for syndrome definition and measurement techniques in clinical research. The Report of an American Academy of Sleep Medicine Task Force. Sleep 1999;22:667-89.

28. Adachi A, Mikami H, Kumanogo A, et al. Clinical significance of pulse rate rise during sleep as a screening marker for the assessment of sleep fragmentation in sleep-disordered breathing. Sleep Med 2003;4:537-42.

29. Fleetham J, Ayas N, Bradley D, et al. Canadian Thoracic Society guidelines: Diagnosis and treatment of sleep disordered breathing in adults. Can Respir J 2006;13:387-92. 


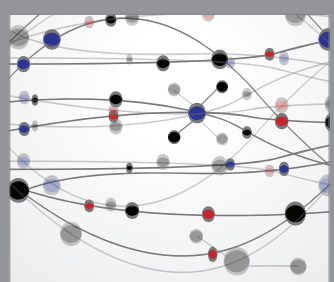

The Scientific World Journal
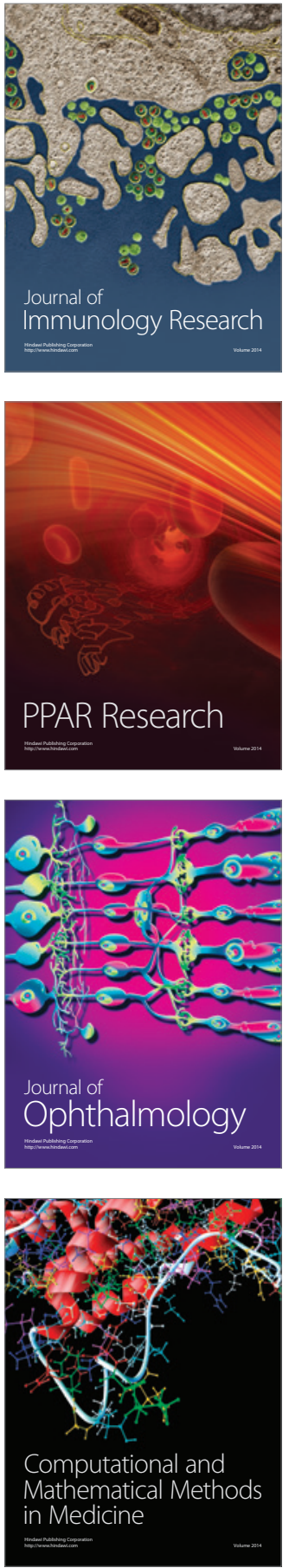

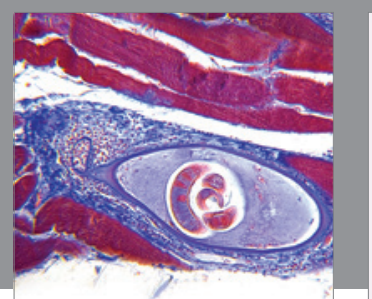

Gastroenterology Research and Practice

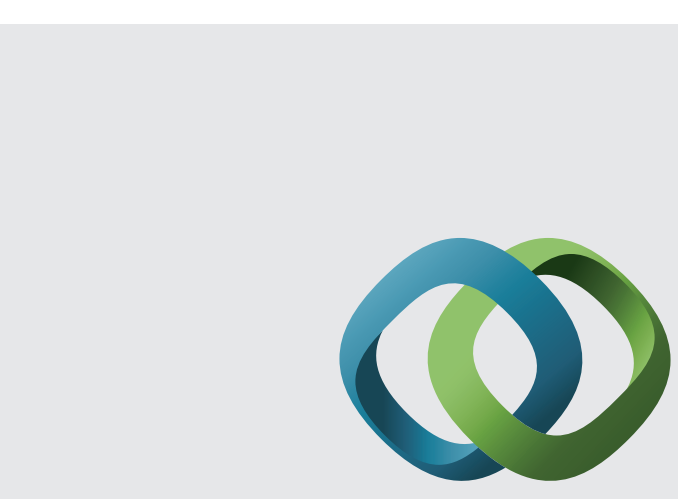

\section{Hindawi}

Submit your manuscripts at

http://www.hindawi.com
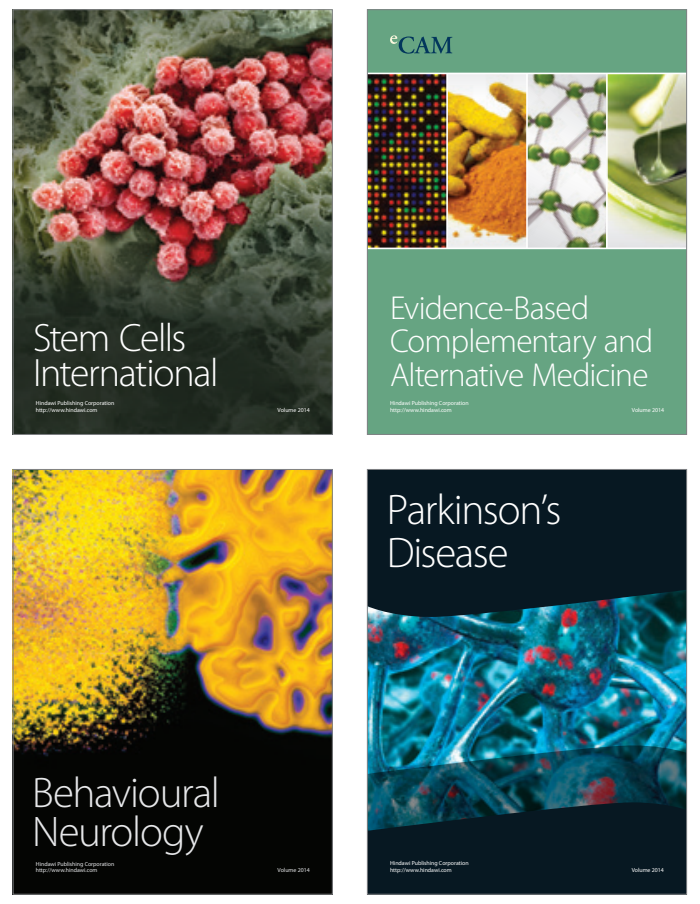
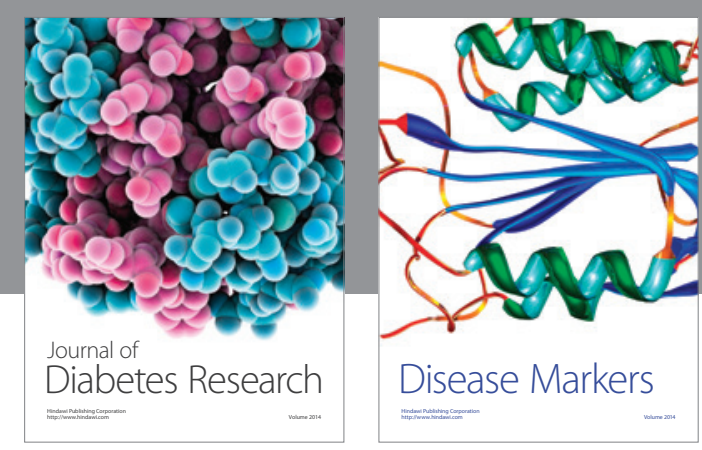

Disease Markers
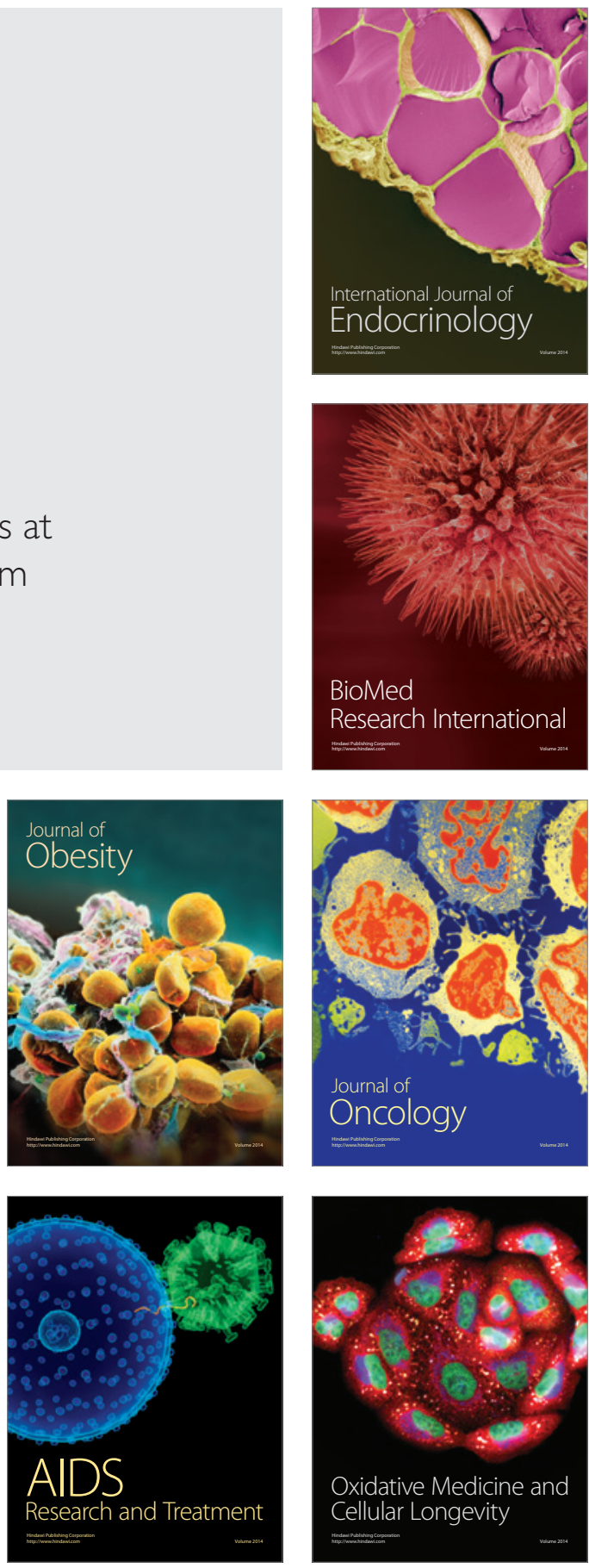